\title{
Study of Pressure Volume Loop in Relation to Radiological Findings among Ventilated Newborn Infants
}

Safaa A El Meneza*1 and Amel Gaber ${ }^{1}$

${ }^{1}$ Faculty of Medicine for Girls, Al Azhar University Cairo, Egypt

*Corresponding author: Faculty of Medicine for Girls, Al Azhar University Cairo, Egypt, Tel: 00202- 6231385; E-mail: safaa5@hotmail.com

Rec date: Jan 09, 2014, Acc date: Mar 12, 2014, Pub date: Mar 14, 2013

Copyright: ( $) 2013$ EL Meneza SA, et al. This is an open-access article distributed under the terms of the Creative Commons Attribution License, which permits unrestricted use, distribution, and reproduction in any medium, provided the original author and source are credited.

\begin{abstract}
Introduction: Pulmonary graphics monitoring of lung during mechanical ventilation have shown a reliable data among many ventilated newborn infants. Exposure of the newborn infants and NICU staff to frequent radiation from X-ray chest carries great risk.
\end{abstract}

Aim of work: The aim of this study is to correlate the chest X-ray changes to the pressure-volume loop findings.

Subjects and methods: Fifty five ventilated newborn infants due to pulmonary disorders as well as fifteen newborn infants due to non-pulmonary causes were included in this study. They all subjected to medical evaluation and care according to the routine of our unit. The findings from X-ray were collected as well as the pressure volume loop monitoring data at the same time. The data were collected and analyzed using SPPS.

Results: There was correlation between pressure volume loop abnormalities and radiological findings of lungs. Newborn infants with RDS whose $\mathrm{X}$ ray chest showed a picture of white out lungs had a slit like pattern of P-V loop. Also cases with increase inspiratory resistance and radiological evidence of chronic lung diseases had widening of pulmonary $\mathrm{P} V \mathrm{~V}$ loop. The study of pressure volume loop can indicate faulty in air flow when showed a flow starvation pattern. Segmental radiological abnormalities did not correlate with pressure volume loop anomalies. Non pulmonary cases did not show neither abnormal X-ray nor P-V loop abnormalities.

Conclusion: Pressure-volume loop provides useful information on the dynamic trends of the respiratory system compliance and resistance. Modern ventilators provide complete monitoring of respiratory system mechanics, which is our guideline for optimizing ventilatory support and avoiding complications associated with mechanical ventilation.

Pressure volume loop abnormal changes can correlate significantly with the generalized lung diseases. Several studies are needed to bring more evidence to our results.

Keywords: Pressure volume loop; Newborn infants; X-ray
Abbreviations
RDS: Respiratory Distress Syndrome; P-V loop: Pressure Volume loop

\section{Introduction}

The optimal treatment for respiratory failure among newborn infants need meticulous diagnosis and ventilator support $[1,2]$. However, despite all the advances of methods of diagnosis, X-ray chest still the gold standard for definite diagnosis of respiratory tracts disorders. The majority of the infants requiring mechanical ventilation in the current neonatal intensive care units are exposed to radiology for several times as well as the NICU staff. This has created challenges to ensure high quality and safe practice in NICUs.

The development of the microprocessor technology has offered opportunity to monitor lung function during mechanical ventilation.
It helps better physiological characterization and quantification of respiratory status, to assess the effectiveness of mechanical ventilation, pharmacological therapy and to guide weaning and extubation [3].

Pressure volume loop relationship describes the pattern of tidal volume as a function of driving pressure. The slope of pressure volume loop represents the elasticity of the lungs. Based upon the location of the pressure volume $(\mathrm{p}-\mathrm{v})$ loop on the total respiratory $\mathrm{p}-\mathrm{v}$ relationship the shape of the $\mathrm{p}-\mathrm{v}$ loop may be altered and may indicate either pressure or volume over distention. The inspiratory and expiratory portions of the $\mathrm{p}-\mathrm{v}$ loop describe a hysteresis that represents the resistive work of breathing [4]. Pressure-volume loops essentially are looking at compliance (change in volume for a given change in pressure). However, they also can give information about overinflation, prolonged inspiration, and leaks.

The distortion of the PV loop may indicate disturbances in the lung mechanics. The PV loop helps to optimize inflation and adequate tidal volume delivery. Inadequate hysteresis may also be indicative of inadequate flow.

Preventing morbidities associated with mechanical ventilation still a major concern despite the availability of several modalities of 
ventilation and real time pulmonary graphics. There is no real consensus as to how to optimize ventilation based on real time pulmonary graphics as no large randomized studies or evidence supporting that ventilator management based on pulmonary graphics reduce alveolar over distension, barotrauma or chronic lung disease.

Assessment of real time pulmonary graphics is now the accepted standard of care in most neonatal intensive care units in the USA [5]. However, still no studies looking for relations of chest X-ray to the curves and loops of the pulmonary graphics.

The question of this study: Does interpretation of P-V loop during mechanical ventilation of newborn infants is equal to chest X-ray findings.

Our objective is to minimize the radiological hazardous and improve quality of care and safety among newborn infants as well as NICUs staff.

In the present study we investigate the relationship between chest $\mathrm{x}$ ray findings and the abnormalities of pressure volume loop among ventilated newborn infants with respiratory distress due to pulmonary disorders.

\section{Patients and methods}

This study is a prospective observational cross-sectional study performed between July 2009-July 2010 in NICU of Al Zahraa University Hospital of Faculty of Medicine for Girls, Al Azhar University, Cairo, Egypt.

The study population included a total of fifty five ventilated newborn infants who suffered from respiratory distress due to respiratory distress syndrome (RDS), Meconium Aspiration Syndrome (MAS), congenital pneumonia chronic lung disease, and pulmonary hypertension and 15 ventilated cases with non-pulmonary causes.

Inclusion criteria: All neonates admitted to neonatal intensive care unit (NICU) with respiratory distress requiring mechanical ventilation.

Exclusion criteria: Infants with congenital heart disease and major congenital anomalies

All patients were subjected to full history taking and thorough clinical evaluation and treatment according to the routine of our unit. Gestational age estimation was done using Ballard score [6].The severity of respiratory distress was measured by Silverman's score [7], (Silverman, 1992) and Downs score [8]. Radiological evaluation in form of chest $\mathrm{x}$ ray and laboratory investigations as CBC, CRP, blood gases was done. Continuous data record of bed side monitoring of pulmonary graphics to all ventilated cases. The ventilators take only 10 $s$ and the entire procedure, including the analysis of the characteristics of the pressure-volume curves, takes around $2 \mathrm{~min}$; the loss of volume due to oxygen uptake by the lungs is negligible; and the technique is simple to carry out at the bedside without the need for any special equipment other than a ventilator [9].

The cases showed abnormal blood gases, abnormal $\mathrm{x}$-ray and abnormal p-v loop records. Infants with non-pulmonary disorders had no radiological abnormalities.

We compared the results of chest $\mathrm{x}$ ray to the hysteresis area obtained from the pressure volume loop and correlated this with presence of unilateral, bilateral, focal, generalized opacity, consolidation, or hyperinflation of lungs. Radiological interpretations considered ray normal if chest X-ray showed adequate chest expansion and posterior intercostal space at 8 .

\section{Results}

Our results are shown in Table 1 to 8

\begin{tabular}{|l|l|}
\hline Data & Mean \pm SD Range \\
\hline $\begin{array}{l}\text { GA (wks.) Mean } \pm \text { SD } \\
\text { (range) }\end{array}$ & $35.18 \pm 2.5(28-40)$ \\
\hline Full term/Preterm & $11 / 44$ \\
\hline $\begin{array}{l}\text { Weight (g.) Mean } \pm \text { SD } \\
\text { (range) }\end{array}$ & $\begin{array}{l}2537 \pm 629.5 \\
(1300-3900)\end{array}$ \\
\hline $\begin{array}{l}\text { Gender } \\
\text { (M/F) }\end{array}$ & $\begin{array}{l}33 / 22 \\
60 \% / 40 \%\end{array}$ \\
\hline $\begin{array}{l}\text { APGAR Mean } \pm \text { SD } \\
\text { (range) }\end{array}$ & $\begin{array}{l}7 \pm 1.3 \\
(4-9)\end{array}$ \\
\hline $\begin{array}{l}\text { Silverman score Mean } \pm \text { SD } \\
\text { (range) }\end{array}$ & $\begin{array}{l}6.45 \pm 1.4 \\
(4-9)\end{array}$ \\
\hline $\begin{array}{l}\text { Downes score Mean } \pm \text { SD } \\
\text { (range) }\end{array}$ & $\begin{array}{l}6.29 \pm 1.5 \\
(4-9)\end{array}$ \\
\hline
\end{tabular}

Table 1: Basic details of ventilated newborn infants included in the study

\begin{tabular}{|l|l|}
\hline Studied parameters & $\begin{array}{l}\text { Mean } \pm \text { SD } \\
\mathrm{N}(\%)\end{array}$ \\
\hline $\begin{array}{l}\text { pH Mean } \pm \mathrm{SD} \\
\text { (range) }\end{array}$ & $7.14 \pm 0.17$ \\
\hline Pa Co2 mmHg Mean \pm SD & $(6.40-7.30)$ \\
(range) & $55.81 \pm 7.5$ \\
\hline Pa O2 mmHg Mean \pm SD & $(42.8-75)$ \\
(range) & $57 \pm 7.12$ \\
\hline BE Mean \pm SD & $(47-70)$ \\
\hline C-reactive protein & $-15.34 \pm 6.7$ \\
Negative /Positive & $(-25-3.6)$ \\
\hline
\end{tabular}

Table 2: The laboratory results of the studied cases

\begin{tabular}{|l|l|}
\hline Cases & Number (\%) \\
\hline Respiratory distress: Pulmonary causes & $55(100)$ \\
\hline Respiratory distress syndrome & $29(52.7)$ \\
Congenital pneumonia & $12(21.8)$ \\
Chronic lung disease(BPD) & $10(18.2)$ \\
MAS & $4(7.2)$ \\
\hline
\end{tabular}


Citation: Safaa A. El Meneza and Amel Gaber (2014) Study of Pressure Volume Loop in Relation to Radiological Findings among Ventilated Newborn Infants. J Neonatal Biol 3: 130. doi:10.4172/2167-0897.1000130

Page 3 of 5

Respiratory distress : non pulmonary causes $15(100)$

Table 3: Clinical diagnoses of the studied cases

\begin{tabular}{|l|l|}
\hline Pressure -volume loop configuration & Number (\%) \\
\hline Normal & $7(12.7)$ \\
\hline Narrow hysteresis & $33(60)$ \\
\hline Expiratory resistance & $10(18.2)$ \\
\hline Beaking & $3(5.5)$ \\
\hline Flow starvation & $1(1.8)$ \\
\hline Shift to left & $1(1.8)$ \\
\hline Total & $55(100)$ \\
\hline
\end{tabular}

Table 4: Pressure volume loop abnormalities among studied cases

There was correlation between pressure volume loop abnormalities and bilateral radiological findings of lungs. Newborn infants with RDS

\begin{tabular}{|c|c|c|c|c|c|c|c|c|}
\hline \multirow[t]{2}{*}{ Clinical diagnosis } & \multirow[t]{2}{*}{ Radiological findings of lungs } & \multicolumn{6}{|l|}{ PVL } & \multirow{3}{*}{$\begin{array}{l}\text { Total } \\
26\end{array}$} \\
\hline & & Normal & Narrow & $\begin{array}{l}\text { Expiratory } \\
\text { resistance }\end{array}$ & Beaking & Flow starvation & $\begin{array}{l}\text { Shift to } \\
\text { left }\end{array}$ & \\
\hline $\begin{array}{l}\text {-RDS [18] } \\
\text {-Congenital } \\
\text { pneumonia [6]-MAS } \\
{[2]}\end{array}$ & Bilateral granularity (ground glass) & 2 & 23 & - & - & 1 & - & \\
\hline $\begin{array}{l}\text { BPD [10] } \\
\text { MAS [1] }\end{array}$ & $\begin{array}{l}\text { Bilateral opacity and } \\
\text { emphysema(bubble) }\end{array}$ & - & 3 & 8 & - & - & - & 11 \\
\hline Severe RDS [11] & Whiteout & - & 7 & 2 & 2 & - & - & 11 \\
\hline $\begin{array}{l}\text { Congenital } \\
\text { pneumonia [6] }\end{array}$ & Unilateral opacity & 5 & - & - & - & - & 1 & 6 \\
\hline \multirow{2}{*}{$\begin{array}{l}\text { MAS [1] } \\
\text { PPHN }\end{array}$} & Air trapping & - & - & - & 1 & - & & 1 \\
\hline & Total & 7 & 33 & 10 & 3 & 1 & 1 & 55 \\
\hline
\end{tabular}

Table 6: Relation between chest $\mathrm{X}$ ray and pressure volume loop findings

\begin{tabular}{|l|l|l|}
\hline P-V loop & Unilateral & Bilateral \\
\hline Abnormal loop & 1 & 47 \\
\hline Normal loop & 5 & 2 \\
\hline Total & 6 & 49 \\
\hline Chi square $30.05, p=0.00000124$ & \\
\hline
\end{tabular}

Table 7: Difference between bilateral and unilateral lesions whose X-ray chest showed a picture of white out lungs had a slit like pattern of $\mathrm{P}-\mathrm{V}$ loop. Also cases with increase inspiratory resistance and radiological evidence of chronic lung diseases had widening of pulmonary P V loop. The study of pressure volume loop can indicate faulty in air flow when showed a flow starvation pattern. Segmental radiological abnormalities did not correlate with pressure volume loop anomalies.

\begin{tabular}{|l|l|}
\hline Radiological findings of lungs & Number (\%) \\
\hline Bilateral granularity opacities (ground glass) & $26(47.4)$ \\
\hline $\begin{array}{l}\text { Bilateral opacity and emphysema/bubble/compensatory } \\
\text { hyperinflation }\end{array}$ & $11(20)$ \\
\hline Whiteout & $11(20)$ \\
\hline Unilateral opacity of the upper lobe & $6(10.6)$ \\
\hline Air trapping & $1(1.8)$ \\
\hline
\end{tabular}

Table 5: Plain chest X-ray abnormalities among studied cases

\section{Discussion}

Many advances have been made in pulmonary function testing during mechanical ventilation in newborn infants and the techniques and equipment are available for beside ventilator measurements.

The pressure volume curve is one of the data that expressed by majority of ventilator monitoring system. The relationship of volume to pressure reflects compliance. Thus the P-V loop shows how compliance develops as volume increases. The work of breathing is best displayed on a pressure-volume curve of one respiratory cycle. The loop has different pathways for inspiration and expiration, known as hysteresis. The total work of breathing of the cycle is the area contained in the loop [10]. 


\begin{tabular}{|l|l|l|l|l|}
\hline Sensitivity & Specificity & PPV & NPV & Prevalence \\
\hline $87.27 \%$ & $100 \%$ & $100 \%$ & $68,18 \%$ & 90.16 \\
\hline
\end{tabular}

Table 8: Sensitivity and specificity of PVL

To define the relation between the mechanical properties of the lungs in newborn infants with respiratory distress due to pulmonary causes, the $\mathrm{P}-\mathrm{V}$ loop and chest $\mathrm{X}$ ray findings were evaluated among 55 ventilated newborn infants due to respiratory distress from pulmonary disorders and 15 ventilated newborn infants due to nonpulmonary lesions.

Our study showed that $(52.7 \%)$ of ventilated newborn infants due to pulmonary disorders was due to RDS, $(21.8 \%)$ congenital pneumonia, (18.2\%) BPD and (7.2\%) due to MAS. The diagnosis based on clinical data and confirmed by chest X-ray.

Evaluation of pressure volume loop had shown various abnormalities in hysteresis among $87.3 \%$ of ventilated newborn infants due to pulmonary disorders. Narrow hysteresis was seen in $60 \%$ of cases whose chest $\mathrm{X}$ ray reveled bilateral granular opacities. All cases with severe RDS had whiteout lungs and had abnormal P-V loop in form of narrow loop in seven cases, expiratory resistance in two cases and breaking in two cases. In neonatal respiratory distress syndrome, compliance is extremely low and at the lowest point of the P-V loop, as lungs show minimal changes in volume per unit pressure change. When pressure volume loop moves towards residual volume, it indicates the severity of atelectasis. These findings agreed with those of Henzler et al. 2007 who stated that parameters derived from the pulmonary pressure volume curve, indicate recruitment in experimental lung injury [11]. As compliance decreases and lung becomes less elastic, the P-V loop in volume-controlled ventilation takes an increasingly flat course. The change in steepness of the inspiratory branch of the PV loop is proportional to the change in lung compliance.

Rajiv PK 2010 studied CPAP application on newborn with RDS reported that patients with ground glass appearance and white out had $\mathrm{P}-\mathrm{V}$ loop with market shift to the right (slit like appearance) as pressure increases (step wise) the $\mathrm{x}$-ray improves and start to inflate as evidenced by posterior rib position, the pressure volume loop start to open and move to the left and pco2 start to decrease these results agreed with[12].

The distortion of the PV loop may indicate disturbances in the lung mechanics. The PV loop helps to optimize inflation and adequate tidal volume delivery avoiding over inflation. Inadequate hysteresis may also be indicative of inadequate flow. The pressure volume loop may be used to determine the change in compliance after surfactant therapy as the loop will become more vertical with better inflation with improving compliance [13].

Narrow pressure volume loop among cases with bilateral lung lesions (granularity and opacities) was the most significant abnormal forms. This may be due to the fact that majority of the studied cases suffered from RDS, pneumonia and BPD which greatly affect the pulmonary compliance .

Interpretation of chest $\mathrm{x}$-ray showed that $20 \%$ of cases had bilateral opacity and, alveolar distension/ emphysema; 18.2\% had BPD and $7.2 \%$ due to MAS. All of these cases had abnormal P-V loop in form of narrow loop in three cases and expiratory resistance in eight cases.
Lung volume is also related to airway resistance. At low lung volumes airway resistance is high and since atelectasis is not resolved, work of breathing is high.

The change in resistance during constant flow ventilation changes the position of the inspiratory branch of the loop while its steepness remains unchanged. This steepness of the inspiratory loop will reflect the elastance of thorax and lung.

So changes in the shape of volume - flow loop are used to obtain information about airway resistance [14].

The increased flow resistance is due in part to fibrosis and loss of lung units with functional loss of the attendant airways

Also P-V loop section reflecting lung over-extension, over distension from too great an inspiratory volume will show up as a bird-like beak as the lung's maximum volume is reached in the face of continued inspiratory flow. The point at which this line begins to flatten and form the beak is the upper inflection, so if the loop starts to become flatter in the upper (last) part of the inspiratory branch, then this could be an indication of over extension of certain areas of the lung. That is, as the lungs become full, further application of pressure does not result in any appreciable increase in tidal volume. This is recognized as "beaking" on the loop.

Over distension may be a result of too high peak inspiratory pressures. Too long an inspiratory time and too high peak end expiratory pressure (PEEP)

The appropriate strategy to combat this will depend on the underlying reason. We recorded beaking among two cases with severe $\mathrm{RD}$ and one case of MAS complicated with PPHN. So avoiding tidal hyperinflation and tidal recruitment has been proposed to prevent ventilator-associated lung injury.

One of our cases showed air trapping and beaking of the P-V loop. P-V loop will also help to optimize inflation if the loop has a "beaked" appearance. In such situations either the pressure or the volume will need adjustment to correct the over inflation of the lung. PV loop could also be used to optimize PEEP [13]. The loop will not meet at the bottom with air trapping or leaks.

The pressure-volume relationship permits assessment of the mechanical properties of the respiratory system at different levels of lung inflation.

Radiological unilateral opacity of the lung was seen in six cases, 5 cases did not show abnormities in configuration of $\mathrm{P}-\mathrm{V}$ loop this significant difference may be due to the compensatory effect of the healthy lung units.

Pressure volume loop has high $(87.27 \%)$ sensitivity in detection of actual positive abnormal lung volume when there are bilateral granular, opacities and consolidations as detected by chest $\mathrm{X}$ ray. It can be used to detect abnormal pulmonary lesions as RDS, pneumonia, BPD and MAS. This high specificity means a high probability of the presence of disorders. Also negative findings can rule out pulmonary lesions. It has $100 \%$ specificity which means that $\mathrm{P}-\mathrm{V}$ loop correctly identifies all patients without pulmonary lesions.

Our study has several limitations. First the small number of studied cases. Second, our cases did not capture all aspects of neonatal pulmonary disorders. Third we did not confirm non pulmonary cases with computed tomography. 
Citation: Safaa A. El Meneza and Amel Gaber (2014) Study of Pressure Volume Loop in Relation to Radiological Findings among Ventilated Newborn Infants. J Neonatal Biol 3: 130. doi:10.4172/2167-0897.1000130

Page 5 of 5

\section{Conclusions}

Parameters derived from the PV curve may help in characterizing the lung aeration and in indicating recruitment in bilateral pulmonary disorders. Alveolar recruitment can be predicted from airway pressure-lung volume loops. Abnormal pressure volume loop indicates high probability of the presence of disease. P-V loop predicted changes in chest $\mathrm{X}$ ray with sensitivity $87.2 \%$ of and specificity of $100 \%$.

Bedside pulmonary graphics should be used as an additional tool complementing clinical examination, blood gas measurements, oximetry trends and chest X-ray evaluation in the management of ventilator supported neonates.

\section{References}

1. Sekar KC, Corff KE (2009) To tube or not to tube babies with respiratory distress syndrome. J Perinatol 29 Suppl 2: S68-72.

2. Stevens TP, Blennow M, Soll RF (2004) Early surfactant administration with brief ventilation vs selective surfactant and continued mechanical ventilation for preterm infants with or at risk for respiratory distress syndrome. Cochrane Database Syst Rev 3: CD003063.

3. Reiterer F, Kuttnig-Haim M, Müller W (1994) [Diagnosis of lung function in intensive care of newborn infants]. Wien KlinWochenschr 106: 181-186.

4. Bhutani VK, Sivieri EM (2003) Pulmonary function and graphics. Assisted ventilation of the neonate (4thedtn) Saunders/Elsevier, Philadelphia 293-309.
5. Bhutani VK, Sivieri EM (2001) Clinical use of pulmonary mechanics and waveform graphics. ClinPerinatol 28: 487-503, v.

6. Ballard JL, Khoury JC, Wedig K, Wang L, Eilers-Walsman BL, et al. (1991) New Ballard Score, expanded to include extremely premature infants. J Pediatr 119: 417-423.

7. Silverman WA, Andrsen DH (1956) Silverman score .pediatrics 1-10.

8. Downes JJ, Vidyasagar D, Boggs TR Jr, Morrow GM 3rd (1970) Respiratory distress syndrome of newborn infants. I. New clinical scoring system (RDS score) with acid--base and blood-gas correlations. ClinPediatr (Phila) 9: 325-331.

9. Qin Lu, Jean-Jacques Rouby (2000) Measurement of pressure-volume curves in patients on mechanical ventilation: methods and significance. Crit Care 4: 91-100.

10. Becker MA, Donn SM (2007) Real-time pulmonary graphic monitoring. ClinPerinatol 34: 1-17, v.

11. Henzler D1, Hochhausen N, Dembinski R, Orfao S, Rossaint R, et al. (2007) Parameters derived from the pulmonary pressure volume curve, but not the pressure time curve, indicate recruitment in experimental lung injury. AnesthAnalg 105: 1072-1078, table of contents.

12. Rajiv PK (2010) Ventilator Graphics in "Essentials of Neonatal Ventilation".

13. Sekar KC (2010) Trends in conventional mechanical ventilation and pulmonary graphics in the newborn. Chin Med J (Engl) 123: 3319-3325.

14. Ranieri VM, Giuliani R, Fiore T, Dambrosio M, Milic-Emili J (1994) Volume-pressure curve of the respiratory system predicts effects of PEEP in ARDS: "occlusion" versus "constant flow" technique. Am J RespirCrit Care Med 149: 19-27. 